\title{
DESIGN, SIMULATION AND PERFORMANCE EVALUATION OF VERTICAL AXIS HELICAL WIND TURBINE
}

\author{
Bikash Karki*1 $^{*}$ Ashok Subedi ${ }^{1}$, Himal Sigdel ${ }^{1}$ and Pradeep Bartaula ${ }^{1}$
}

\begin{abstract}
This report is all about the design, simulation, fabrication, and performance evaluation of the VAHWT. The experimental data obtained via testing and data from CFD approach are used for performance evaluation. From the data obtained experimentally, the VAHWT so fabricated has been found to operate at the low cutin speed of $3.18 \mathrm{~m} / \mathrm{s}$ and maximum power output has been found to be 2.656 watts at the wind speed of $8 \mathrm{~m} / \mathrm{s}$. The maximum rpm of the rotor blade is recorded to be $\mathbf{7 2 2 . 2}$ $\mathbf{r p m}$ at the velocity of $11.53 \mathrm{~m} / \mathrm{s}$ signifying its potentiality of wind power production. Besides, the data so obtained from both the process when analyzed through graph plots, has shown the similar nature slope wise. This simply signifies the generation of satisfactory data via experiment. In addition, the mechanical losses has shown difference between the experimental and data obtained via CFD approach. At the end, when applying CFD approach for evaluation of maximum efficient turbine varying the aspect ratio, has shown the turbine with aspect ratio of 0.6531 to be the most efficient with performance coefficient of $36.396 \%$. However due to limitation in RPM and Test rig, the rotor blade with aspect ratio of 0.6956 was fabricated and used for evaluation experimentally. The data so obtained from both the process were concluded to be relevant to each other. Thus, the detail study on this project has led to the need and opportunity of VAHWT to be further researched and can be developed as a good source of energy producing system. It can also be economical method of power extraction from wind in the countries like Nepal with growing urbanization.
\end{abstract}

\section{Introduction}

Wind energy technology has become one of the most economical and proven renewable energy technology among all other renewable energy technology in recent years. Wind turbine is a device, which change kinetic energy of the wind to mechanical energy. The wind turns the blades, which spin a shaft, which connects to a generator and makes electricity. There are two types of wind turbine commonly used are Horizontal Type and Vertical Type.

Helical wind turbines look like DNA structures, large drill bits or other spiral designs, which catch the wind and produce electricity. Typically, helical wind turbines are

Institute of Engineering, Pashchimanchal Campus, P.O. Box : 46, Lamachaur-Pokhara, a Final Year Project Report for the partial fulfillment of the requirementsfor the award of the degree of Bachelor of Engineering in Mechanical Engineering, 2017.

Corresponding author:

E-mail : info@wrc.edu.np 
designed along a vertical axis. Helical wind turbines can be mounted on rooftops, in yards, at airports or other settings depending upon the exact design and application. They can be tower mounted or mounted close to the base. These turbines are less susceptible to problems with crosswinds than bladed turbines and they require no tail fan to keep them pointed in the optimal direction.

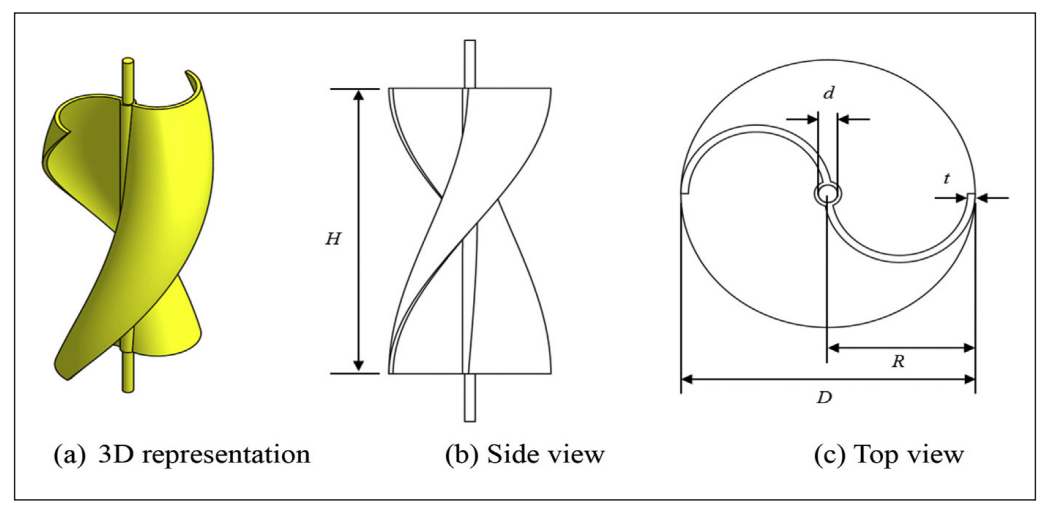

Fig: Vertical axis helical wind turbine

Spiral wind turbine was developed only in late 80 s and its commercial use took peak only in last decade. Looking behind in the history, the first commercial VAWT was developed by French scientist George JM Darrieus ${ }^{[1]}$.

The development of VAWT took a peak only after the first oil crisis in 1970s according to Shikha et al. and Kirke. After the extensive research done by scientist of USA and Canada during 1970s and 1980s culminated with the construction of 4.2 MW vertical axis wind turbine, which gave birth to the commercial use of such wind turbines. ${ }^{[1]}$

Talking about the helical wind turbine, the wind-side wind turbine in Finland is helical VASWT working on sailing engineering principles intended for both inland and marine environments. It is successfully working for past few decades and has an ability to work up to $60 \mathrm{~m} / \mathrm{s}^{[1,5]}$

In recent years, the affordable wind turbines-USA, Wind of Change-Germany and Wind Side-Finland are some of the active organization manufacturing VASWT. The first two have developed 3 range of VASWT, 1 KW 3 bladed, 3KW 3 bladed and $1 \mathrm{KW}$ single bladed turbines which are commercially available. ${ }^{[3]}$

VASWT though have been extensively used for small power production purpose, but it is still on research phase rather than commercial use due to its short fatigue life though it can withstand the wind of velocity $35 \mathrm{~m} / \mathrm{s}$ to $40 \mathrm{~m} / \mathrm{s}$ and maximum up to $60 \mathrm{~m} / \mathrm{s}$.

Thus, the fabrication of the model of proposed VAHWT is based on the working principle of vertical axis Savonius wind turbine. The model was fabricated based on the design of VAHWT WS-0,15B produced by Oy Windside Production Ltd, Finland. There is slight variation in the dimension of the rotor blade to be fabricated with respect to the Windside 
WS- $0,15 \mathrm{~B}$. The diameter of the rotor blade is reduced to $160 \mathrm{~mm}$ and height to $230 \mathrm{~mm}$ as compared to $340 \mathrm{~mm}$ and $515 \mathrm{~mm}$ respectively. The material selection of each part also varies while the shape remains same.

\section{Materials and Methodology}

The goal of this project was to design and fabricate a vertical axis helical wind turbine (VAHWT) that could generate power under relatively low wind velocities. Moreover, the performance analysis of the vertical axis helical wind turbine was also a major part of it. Different steps that were involved in design, simulation and performance analysis of VAHWT are listed as follows:

\section{A. Complete Background Research}

Background research, which includes reviewing a similar projects done by different people in the past, research papers and different books related to helical wind turbine, were studied thoroughly and basis for the project was built.

\section{B. Design}

The design of VAHWT rotor blade with all the necessary components of the turbine was designed based on literature review on CATIA V5R20. The detail stepwise method used in design step is as follows:

\section{Simulation}

Simulation of the VAHWT designed on CATIA V5R20 was performed on ANSYS Workbench 16.0 based on the above considerations. The CATIA file was imported in ANSYS and all the necessary data were obtained through the ANSYS CFD analysis.

\section{Fabrication}

The Fabrication of rotor blade was done at TTL lab, Kathmandu University. The design made in CATIA was used as reference to fabricate the rotor through RPM (3D Printer). While otherassembly parts were fabricated at normal lab conditions using common mechanical machine and technologies. 


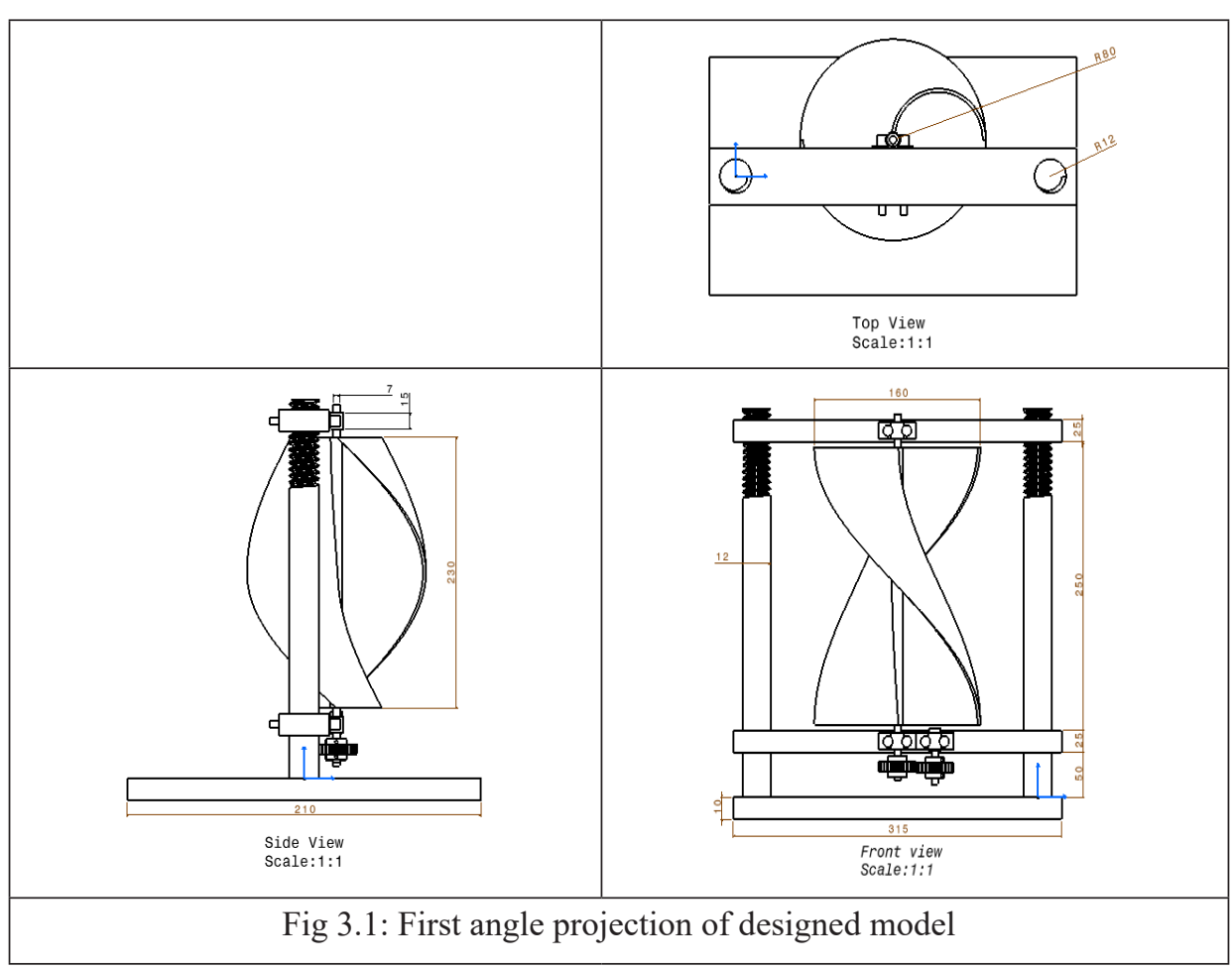

\section{E. Testing}

The testing of the fabricated model was done at Kathmandu University. The existing wind tunnel test rig was used for the testing of the model. The speed of wind was varied from $3 \mathrm{~m} / \mathrm{s}$ to $12 \mathrm{~m} / \mathrm{s}$. The rpm of rotor was measured along with the wind velocity at corresponding time. These data were recorded at the first stage of testing. While, in the second stage, the power was measured through electrical analogy. The varying current was passed to the motor through circuit to oppose the rotor blade as both were connected through the gear of same size. The current at the stopping point was measured and corresponding voltage was noted. Considering no energy loss, power output was assumed to be equal to the power given by motor to stop the rotor blade rotating at particular speed. Hence, the power output was calculated based on electrical analogy. The detail process is as follows:

\section{F. Performance Analysis}

The performance analysis of vertical axis helical wind turbine was carried out by making different curve between wind speed and revolution, wind speed and power output and theoretical power and actual power at different wind speed. The data obtained from the testing and ANSYS workbench were used to generate the various charts and graphs and final conclusion was derived from that. The entire performance analysis was entirely based only on the data generated through testing and fabrication. 


\section{G. Develop Future Design Recommendations}

From the data obtained, recommendations for future studies regarding the potential of vertical axis wind turbine was made. These recommendations are supposed to aid in the development of a technology, reduce energy costs in the average household and better the environment. The VAHWT can be revolutionary concept in the field of green energy and wind energy sector but there should necessarily be some improvements and detail and inside study. The aesthetic part also should be considered.

\section{Results and Discussion}

The rotor designed at CATIA was fabricated at TTL lab, KU and assembled as designed and final model to test was developed. After completion of the fabrication and assembly, the testing of VAHWT was carried out the Wind tunnel of KU.

a. Results via testing

b. Results via CFD analysis

The results were obtained through above two processes and necessary comparison and conclusions were derived.

\section{A. Results via Testing}

The two experiment were performed at the lab to obtain the following data. They are as follows:

a. The velocity and rpm of fabricated modal

b. Power produced by fabricated model of VAHWT

\section{Explanation of this two method are as follows :}

\section{a) The velocity and rpm of fabricated model}

The revolution of the rotor blade at different wind velocity were measured. To be more precise and accurate, 20 sample readings were taken and their average was taken for further calculations. The detail table A.1 is at appendix A while the summarized data of velocity of wind and rpm of the rotor blade are tabulated in the following table.

Table: Summery table of recorded wind velocity and rotational speed

\begin{tabular}{cc|c|c|c|c|c} 
Experiment & $\begin{array}{c}\text { Average } \\
\text { Velocity }\end{array}$ & $\begin{array}{c}\text { Average } \\
\text { rpm }\end{array}$ & $\begin{array}{c}\text { Max } \\
\text { Velocity }\end{array}$ & Max rpm & Min Velocity & Min rpm \\
\hline 1 & 3.71985 & 157.95 & 4.083 & 177.2 & 3.418 & 133 \\
\hline 2 & 4.64015 & 205.43 & 4.831 & 225 & 4.203 & 190.2 \\
\hline 3 & 5.46015 & 271.895 & 5.9 & 310 & 5.01 & 244 \\
\hline 4 & 6.48945 & 337.125 & 6.95 & 359.6 & 6.115 & 315.6 \\
\hline 5 & 7.60541 & 381.375 & 7.92 & 410.6 & 7.125 & 358.4 \\
\hline 6 & 8.57315 & 450.34 & 8.897 & 477.9 & 8.00 & 405.3 \\
\hline 7 & 9.53875 & 547.545 & 9.906 & 588.4 & 9.00 & 496 \\
\hline 8 & 10.5865 & 657.251 & 10.95 & 698 & 10 & 608.6 \\
\hline 9 & 11.094 & 704.01 & 11.41 & 722.2 & 11 & 689.8 \\
\hline
\end{tabular}


From the above table it can be found that, with increase in velocity, the rpm of rotor has been increased. The poor knob adjustment to control the speed of fan/ blower in the wind tunnel caused the variation in the wind velocity at the same knob adjustment. The velocity measured via anemometer seemed fluctuating despite adjusting the knob at one point. Thus 20 readings were taken and average data was considered. The maximum velocity recorded was $11.41 \mathrm{~m} / \mathrm{s}$ and corresponding rpm of rotor was recorded to be $722.2 \mathrm{rpm}$ as measured by tachometer.

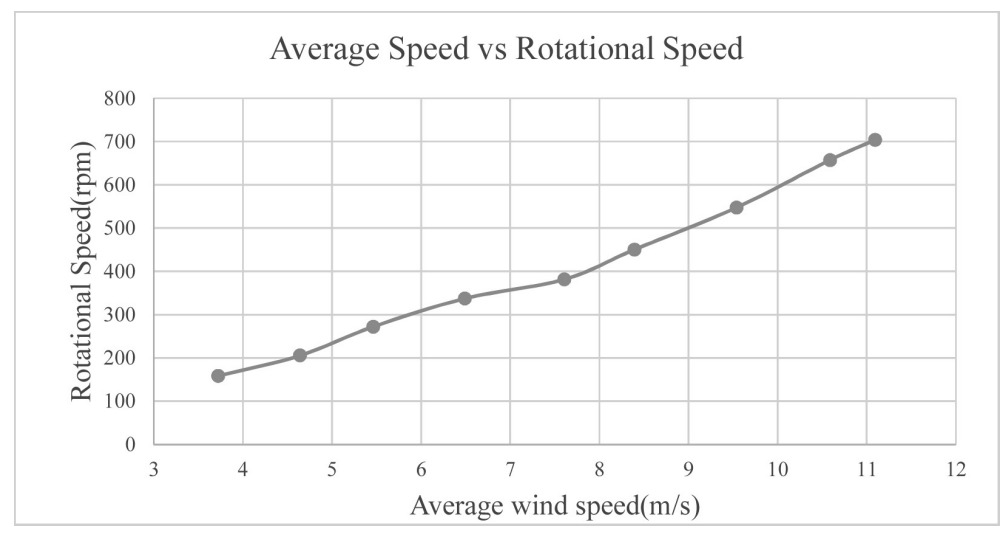

Fig: Average speed vs rotational speed graph

The graph plotted on the basis of the above data in the spreadsheet. The slope of the curve generated seems increasing positively signifying the increase of rotational speed with increase in average wind speed. The line seems almost straight and linear. This shows there is linear relation between the wind speed and rotational speed of rotor. Thus the data generated can be considered quite satisfactory.

\section{b) Power produced by fabricated model of VAHWT}

As the direct power output wasn't feasible to calculate, thus motor control circuit was used to calculate the power output. During which, opposing power was given through the motor to stop the rotating rotor as both motor and rotor were coupled with spur gear of gear ratio 1:1. The current was varied through the circuit so as to provide the power required to stop the rotor at the corresponding wind velocity. Applying the principle of conservation of energy, the electrical power of motor was supposed to be equivalent to the power output of the VAHWT. The current and voltage supplied to the motor to stop the rotor at various wind velocity is in the table below:

This table shows the power produced by the fabricated model in wind tunnel and power produced by same model through CFD. The theoretical power should always be higher than the actual power and similar condition can be observed in the above table too. The ratio of theoretical power to the actual power was calculated and it is tabulated in the above table under the column $\mathrm{C}_{\mathrm{p}}$ which means coefficient of performance. The $\mathrm{C}_{\mathrm{p}}$ is observed to be 15 to $21 \%$ which seems almost relevant in terms of fluctuation. 
Table: Performance Coefficient of fabricated model of VAHWT

\begin{tabular}{c|cccccccc} 
Exp. & $\begin{array}{c}\text { Velocity } \\
(\mathbf{m} / \mathbf{s})\end{array}$ & $\mathbf{r p m}$ & $\begin{array}{c}\text { Voltage } \\
(\mathbf{V})\end{array}$ & $\begin{array}{c}\text { Current } \\
(\mathbf{A})\end{array}$ & $\begin{array}{c}\mathbf{P}_{\text {Exp }} \\
(\mathbf{W})\end{array}$ & $\begin{array}{c}\mathbf{P}_{\text {Th }} \\
(\mathbf{W})\end{array}$ & $\begin{array}{c}\text { Exp. Torque } \\
(\mathbf{N m})\end{array}$ & $\mathbf{C}_{\mathbf{p}}(\mathbf{\%})$ \\
\hline 1 & 4.4 & 190 & 1.2 & 0.24 & 0.288 & 1.92 & 0.01447 & 15 \\
\hline 2 & 5.1 & 250 & 1.48 & 0.31 & 0.4588 & 2.98 & 0.01752 & 15.55 \\
3 & 6.0 & 310 & 2.04 & 0.37 & 0.7548 & 4.86 & 0.02325 & 15.50 \\
4 & 6.8 & 355 & 2.53 & 0.51 & 1.29 & 7.08 & 0.03470 & 18.20 \\
\hline 5 & 7.5 & 370 & 3.12 & 0.65 & 2.028 & 9.501 & 0.05234 & 21.34 \\
6 & 8.0 & 400 & 3.45 & 0.77 & 2.6565 & 11.53 & 0.06342 & 20.03 \\
\hline
\end{tabular}

There can be variation in the actual power because of the motor used to oppose the rotor. As, motor doesn't give the same power output as the generator. But, due to unavailability of generator/alternator for the scaled down model, the motor had to be used to measure the power output. Thus, use of alternator is supposed to yield more accurate and precise data.

\section{A. Results via CFD Analysis}

After testing was carried out at KU the obtained data were compared with the data obtained through the simulation on ANSYS Workbench 16.0. The data obtained from the ANSYS Workbench 16.0 are listed as follows:
a) Torque at different velocity of designed model in ANSYS CFD
b) Effect in performance coefficient of VAHWT varying $b(\mathrm{D} / \mathrm{H})$
c) Comparison of $\mathrm{C}_{\mathrm{p}}$ of fabricated VAHWT generated via $\mathrm{CFD}$ and via experiment
d) Static pressure distribution

Above listed data obtained via ANSYS 16.0 are shown by following tables.

\section{a) Torque at different velocity of designed model in ANSYS CFD}

The velocity and corresponding RPM measured in the lab were taken as the reference input data for the CFD analysis and torque for the respective value of $\boldsymbol{\omega}$ was calculated through the CFD. The value of torque is tabulated as above. Using the torque the power and ratio of theoretical power and power calculated via CFD were calculated

Table: Torque produced by the designed VAHWT at different velocity obtained in the ANSYS CFD

\begin{tabular}{|c|c|c|c|c|c|c|}
\hline Velocity & $\mathbf{r p m}$ & $\boldsymbol{\omega}(\mathbf{r a d} / \mathbf{s e c})$ & Torque & $\mathbf{P}_{\mathbf{C F D}}$ & $\mathbf{P}_{\text {th }}$ & $\mathbf{C}_{\mathbf{P}}$ \\
\hline 3.71985 & 157.95 & 16.54 & 0.017735129 & 0.29431 & 1.16066 & 25.3571 \\
\hline 4.64015 & 205.43 & 21.5125 & 0.027449231 & 0.5905 & 2.2519 & 26.22 \\
\hline 5.46015 & 271.895 & 28.4727 & 0.037288634 & 1.0617 & 3.66916 & 28.93 \\
\hline 6.48945 & 337.125 & 35.3036 & 0.051871813 & 1.83126 & 6.15995 & 29.728 \\
\hline 7.60541 & 381.375 & 39.9374 & 0.069609555 & 2.78 & 9.91564 & 28.036 \\
\hline 8.39315 & 450.34 & 47.1594 & 0.084210461 & 3.97131 & 13.32689 & 29.799 \\
\hline 9.53875 & 547.54 & 57.3380 & 0.1127929 & 6.46731 & 19.56267 & 33.0594 \\
\hline 10.5865 & 657.2505 & 68.8270 & 0.1454562 & 10.0113 & 26.74306 & 37.435 \\
\hline 11.09395 & 701.01 & 73.4095 & 0.151768388 & 11.50828 & 30.77602 & 37.39 \\
\hline
\end{tabular}


From the above data, it can be seen that $C_{p}$ (performance coefficient) ranges from $27 \%$ to $37 \%$. Also, it can be observed that efficiency increased with the increase in rpm and velocity.

b) Effect in change in performance coefficient of VAHWT with change in $b(\mathrm{D} / \mathrm{H})$ The table below gives the change in performance coefficient of the turbine with change in value of $b$ (diameter to height ratio). The diameter was fixed and its height was varied and simulated. The table contains the data generated from the simulation.

Table: Change in Performance coefficient of the turbine with the change in value of b via ANSYS 16.0

\begin{tabular}{|c|c|c|c|c|c|}
\hline \multicolumn{2}{|c|}{ Velocity } & \multicolumn{5}{c|}{$\mathbf{7 . 6 0 5 4 0 5} \mathbf{~ m} / \mathbf{s}$} \\
\hline \multicolumn{2}{|c|}{ Rotational speed } & \multicolumn{4}{|c|}{$\mathbf{3 9 . 9 3 7 4} \mathbf{~ r a d} / \mathbf{s e c}$} \\
\hline Model & Diameter(D) & Height(H) & Torque & $\mathbf{C}_{\mathbf{p}}$ & b=D/H \\
\hline 1 & $160 \mathrm{~mm}$ & $185 \mathrm{~mm}$ & 0.052555406 & 26.3167 & 0.86486 \\
\hline 2 & $160 \mathrm{~mm}$ & $200 \mathrm{~mm}$ & 0.052740102 & 24.4285 & 0.8 \\
\hline 3 & $160 \mathrm{~mm}$ & $215 \mathrm{~mm}$ & 0.07171169 & 30.8985 & 0.74418 \\
\hline 4 & $160 \mathrm{~mm}$ & $230 \mathrm{~mm}$ & 0.069609555 & 28.036 & 0.6956 \\
\hline 5 & $160 \mathrm{~mm}$ & $245 \mathrm{~mm}$ & 0.096250919 & 36.3936 & 0.6531 \\
\hline 6 & $160 \mathrm{~mm}$ & $260 \mathrm{~mm}$ & 0.070262465 & 25.034 & 0.61538 \\
\hline 7 & $160 \mathrm{~mm}$ & $275 \mathrm{~mm}$ & 0.087902851 & 29.61126 & 0.5818 \\
\hline
\end{tabular}

From the above table, it can noticed that there is change in performance coefficient with the change in value of $b(\mathrm{D} / \mathrm{H})$. Altogether seven models were designed varying the value of $b$ in which the diameter was fixed and height was varied from the range of $185 \mathrm{~mm}$ to $275 \mathrm{~mm}$. The value of $\mathrm{C}_{\mathrm{p}}$ was generated through the ANSYS Fluid Fluent Workbench 16.0 via CFD for all 7 models as shown in the table above.

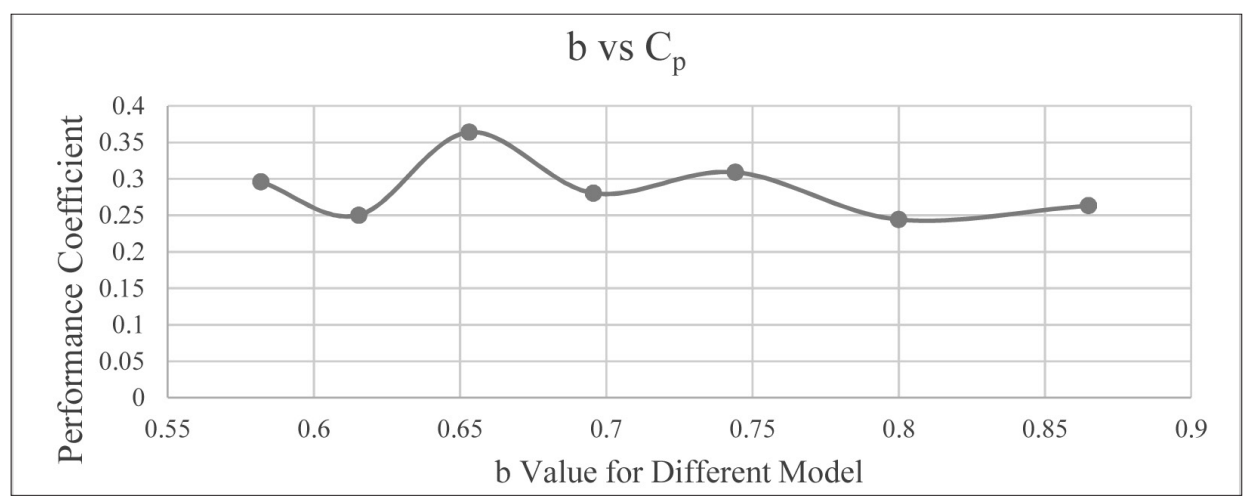

Fig: $b$ vs $C_{p}$ graph in different models

From the data generated, it can be noticed that the maximum $\mathrm{C}_{\mathrm{p}}$ is for the value of $b=0.6531$. Thus, Thus, keeping the value of $b=6.531$ and designing the rotor on same 
basis could be the most economical in terms of efficiency, which has to be experimentally verified. The rotor with the value of $b=0.6956$ was fabricated and its $C_{p}$ is almost $8 \%$ lower than the most efficient rotor as observed via CFD analysis.

\section{c) Comparison of $\mathrm{C}_{\mathrm{p}}$ of fabricated VAHWT generated via $\mathrm{CFD}$ and via experiment}

Based on the above data and table, the comparison of performance coefficient calculated via CFD and measured via experiment has been done in the following table.

Table: Comparison of $\mathrm{C}_{\mathrm{p}}(\mathrm{CFD})$ and $\mathrm{C}_{\mathrm{p}}$ (Exp.) of fabricated VAHWT

\begin{tabular}{c|c|c|c|c|c|c|c|} 
S.N. & Velocity & $\mathbf{r p m}$ & $\mathbf{W}(\mathbf{r a d} / \mathbf{s})$ & Torque (CFD) & Torque (Exp.) & $\mathbf{C}_{\mathbf{p}}(\mathbf{C F D})$ & $\mathbf{C}_{\mathbf{p}}(\mathbf{E x p}$ ) \\
\hline 1 & 4.4 & 190 & 19.8967 & 0.025055358 & 0.0187098 & 25.963 & 15.01 \\
\hline 2 & 5.1 & 250 & 26.1799 & 0.0332334 & 0.0208545 & 29.099 & 15.55 \\
\hline 3 & 6.0 & 310 & 32.4631 & 0.044642295 & 0.0252905 & 29.766 & 15.50 \\
\hline 4 & 6.8 & 355 & 37.1755 & 0.055904594 & 0.0333837 & 29.324 & 18.20 \\
\hline 5 & 7.5 & 370 & 38.746 & 0.067604828 & 0.0426563 & 27.546 & 21.34 \\
\hline 6 & 8.0 & 400 & 41.8879 & 0.075275478 & 0.0468904 & 27.322 & 20.03 \\
\hline
\end{tabular}

From the above table, it can be shown that performance coefficient of VAHWT via CFD is higher than measured value during experimental test. The slope of torque (CFD) and torque (experiment) is presented below and slope of both curves seems almost same thus validating the data generated via CFD and measured via experimental test. Also, the $\mathrm{C}_{\mathrm{p}}$ (CFD) and $\mathrm{C}_{\mathrm{p}}$ (Exp.) curve also depicts similar slope.

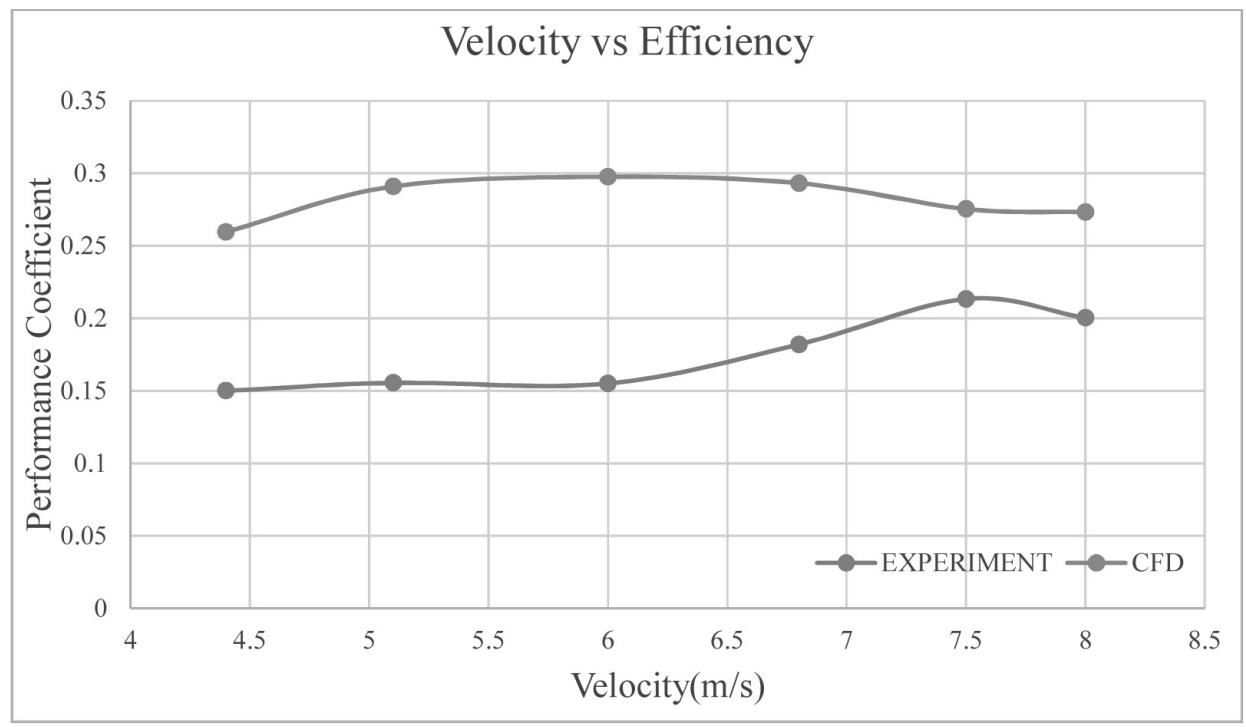

Fig: Wind velocity vs performance coefficient graph

From the above graph, it can be concluded that the value of performance coefficient calculated via experiment ranges from 0.1501 to 0.2003 while via CFD ranges from 0.25963 to 0.27322 in the velocity range of 4.4 to $4.8 \mathrm{~m} / \mathrm{s}$. The experimental data is less compared to CFD because of mechanical losses. The losses may have resulted due 
to fabrication not being according to design, poor mechanical strength of the shaft rod, bearing loss due to smaller size etc. However, the slope of both curve seems almost identical.

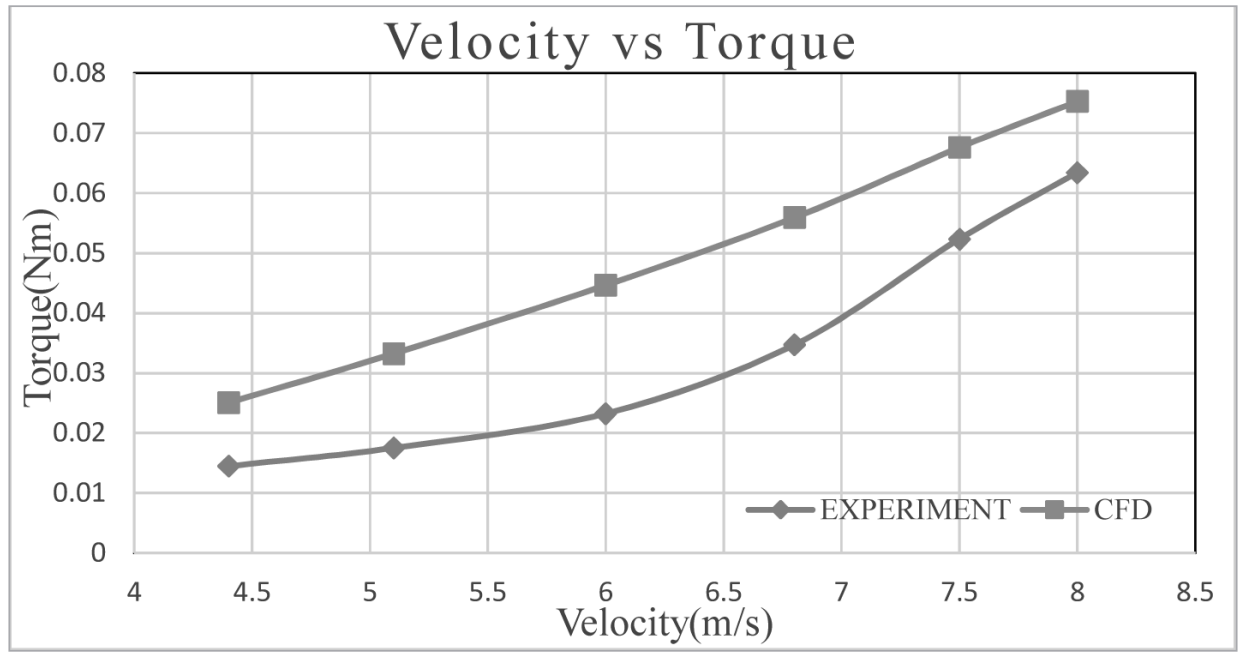

Fig: Wind velocity vs torque graph

The above graph also depicts similar result as above. It can be observed the value of the torque produced experimentally ranges from 0.01871 to 0.04689 while produced via CFD ranges from 0.02505 to 0.07527 . The gap between two values is due to mechanical losses as explained before. However, the slope of both curves are identical which signifies there is uniform increase of torque with respect to wind velocity in both experimental and CFD approach.

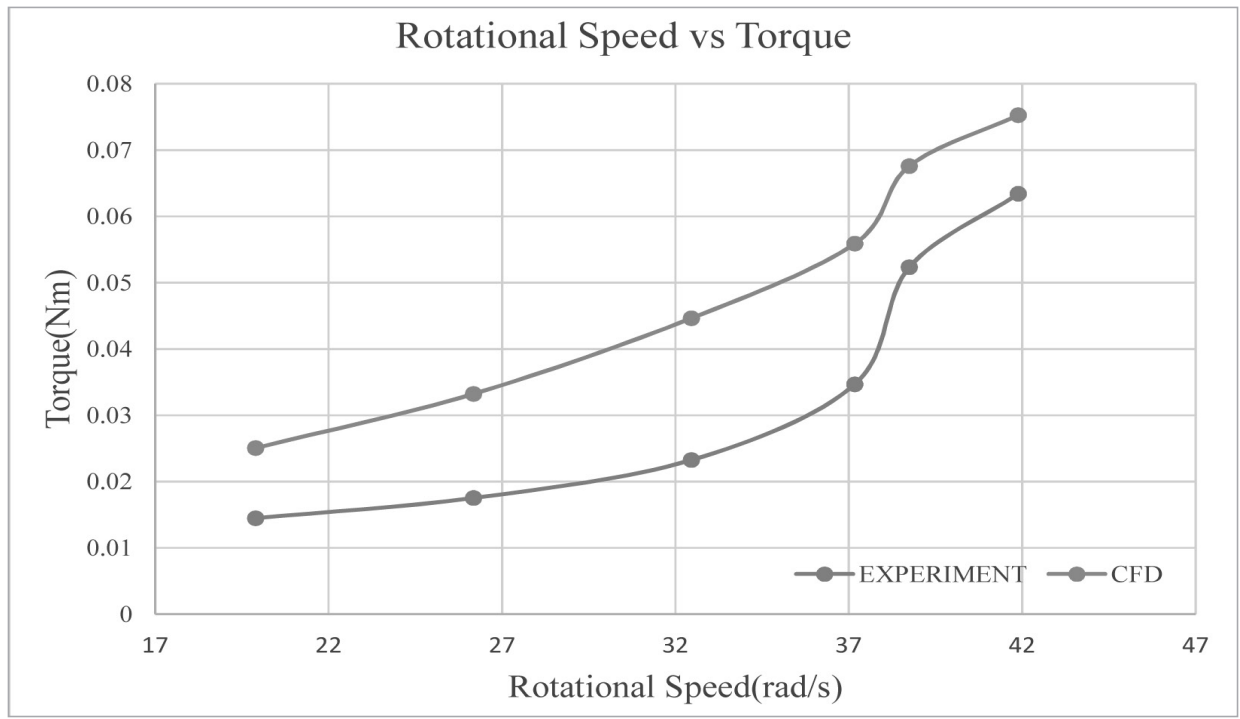

Fig: Rotational speed vs torque graph 
The above graph show the relation between the torque and rotational speed where the slope of both experimental and CFD seems almost same. In this graph too, the experiment data is less compared to the CFD due to some losses.

Thus, from above all graph it can be concluded that the curve so developed using data generated via Experimental and CFD approach are of same trend and similar thus validating the experimental data with the CFD.

\section{d) Static pressure distribution}

Figure below shows the pressure contour at the front and at the outlet side of the turbine model of value of $b=0.6956$ with rotational speed $19.8967 \mathrm{rad} / \mathrm{s}$ for wind speed $4.4 \mathrm{~m} / \mathrm{s}$. Figure below shows that minimum and maximum static pressure at $4.4 \mathrm{~m} / \mathrm{s}$ are -12.76064 pa and 7.902082 pa respectively.

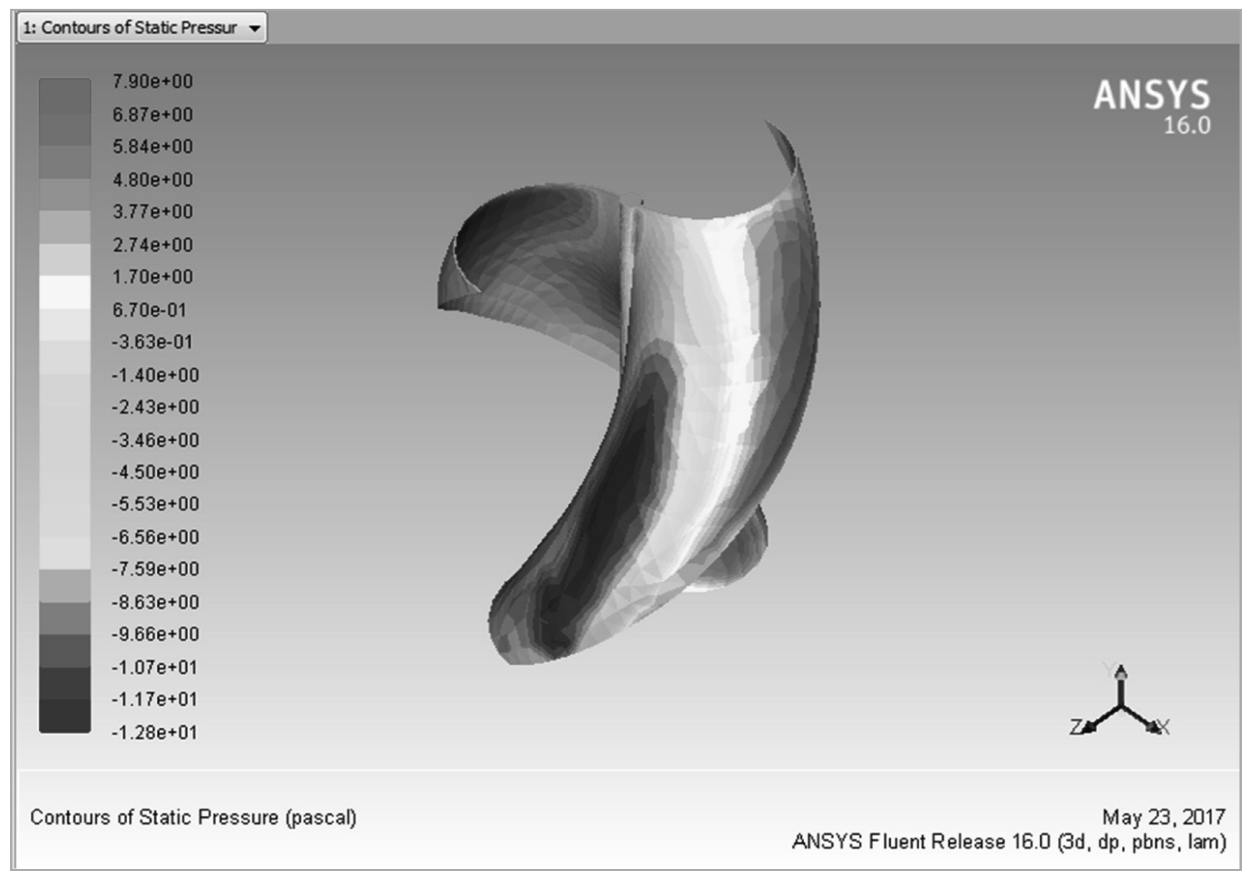

Fig: Contours of static pressure

Figure below shows the pressure contour at the front and at the outlet side of the turbine model of value of $b=0.6956$ with rotational speed $26.1799 \mathrm{rad} / \mathrm{s}$ for wind speed $5.1 \mathrm{~m} / \mathrm{s}$. Figure below shows that minimum and maximum static pressure at $5.1 \mathrm{~m} / \mathrm{s}$ are -26.1773 pa and 16.10538 pa respectively. 


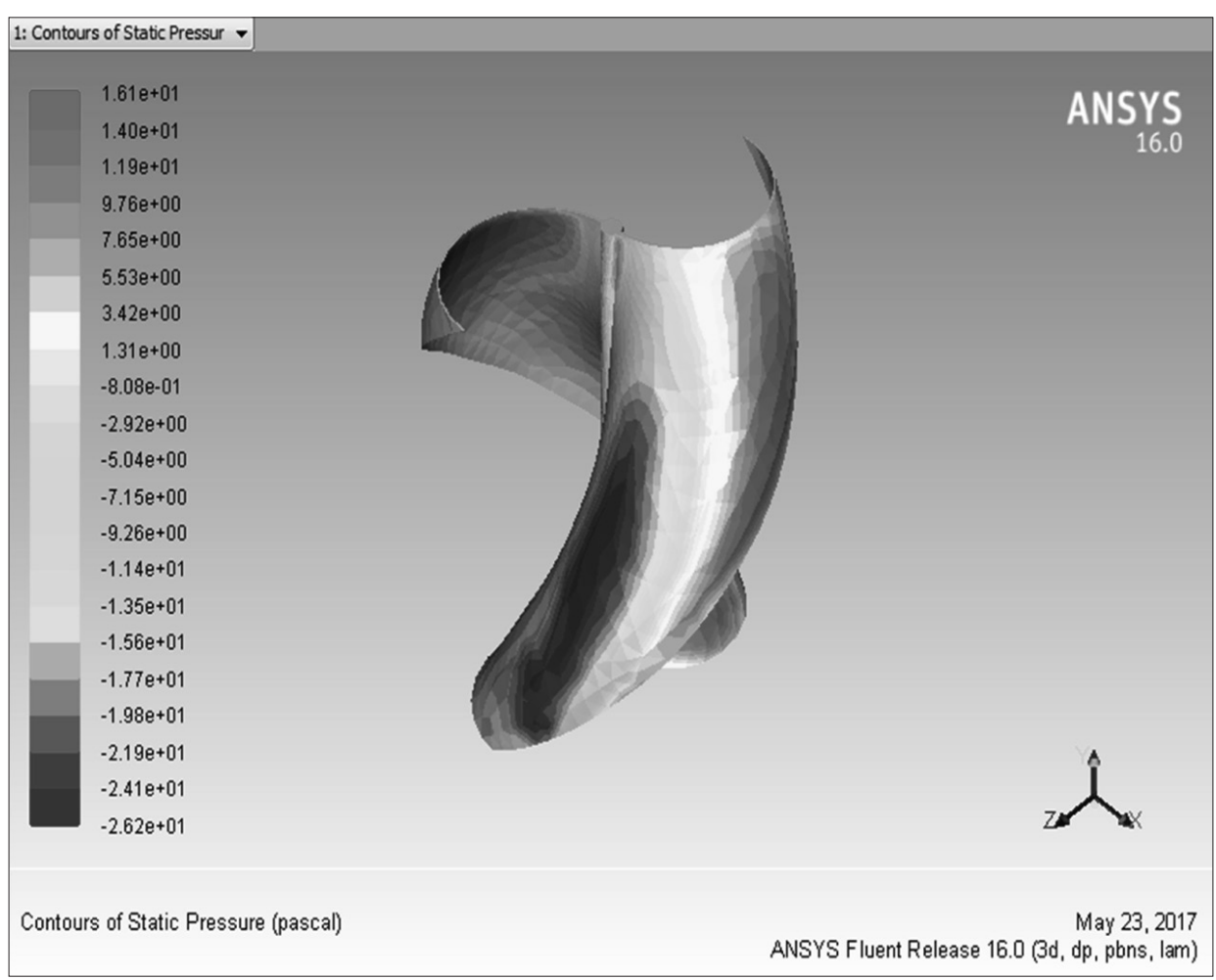

Fig: Contours of static pressure

When the blade is rotating, there is the significant pressure difference in the front side and the rear side of the turbine blade. Due to the spiral surface, the pressure difference i.e. force generates the torque. In general, the front side of the blade has blade higher pressure while the corresponding rear side has a lower pressure. When inflow velocity increases, the pressure difference becomes significant. The pressure difference is large at the blade tip and small at the root. This suggests that significant energy can be extracted near the blade tip. The rear side pressure is negative so the thrust force is transferred to the shaft.

\section{Conclusion}

VAHWT is an innovative wind turbine in the sector of wind energy. The design of the rotor of the turbine developed is based on the wind turbine developed by Windside WS-0,15B. Vertical axis helical wind turbines are special types of VAWT with helical structured rotor blade. These turbines can be mounted on rooftops, in yards, at airports or other settings depending upon the exact design and application due to the low cut-in speed. These turbines are also less susceptible to problems with crosswinds and are much quieter than bladed turbines because of slower speeds along the blade tips. These turbines generate almost no noise and are safe to use in population center, public places, parks, wildlife parks and on top of buildings. They are also aesthetical appealing and in many cases have been used to combine art and functionality. 
The difference in the theoretical power and experimental power observed is due to mechanical losses of the model. The mechanical losses can be due to error in fabrication, poor mechanical strength of the brass rod used as shaft causing some eccentricity, bearing losses because of small size, error in readings obtained from the electric circuit as there could be motor losses, and power losses because of circuit itself etc. The graphs so plotted verifies the differences and losses can be easily traced.

The $\mathrm{C}_{\mathrm{p}}$ at different aspect ratio $(\mathrm{D} / \mathrm{H})$ keeping diameter constant, was calculated by CFD approach and maximum $\mathrm{Cp}$ of $36.396 \%$ is found for the value of $b=0.6531$. Thus, the turbine with $b=0.6531$ is considered to be the most economical. However, the rotor with the value of $b=0.6956$ was fabricated and its $\mathrm{Cp}$ is almost $8 \%$ lower than the most efficient rotor as observed via CFD analysis.

It has led to the need and opportunity of VAHWT to be further researched and can be developed as a good source of energy producing system. The features like low cut in speed, noise free production, low height placement and aesthetic functionality suggest that it can be proven to be economically feasible power extraction from wind in the countries like Nepal with growing urbanization.

The design can be further modified with variation in the aspect ratio, choosing better materials for shaft and bearings, use of alternator etc. can make it more efficient and reliable.

\section{Acknowledgement}

The final year project on design, simulation, fabrication, and performance evaluation of VAHWT has been a great chance for learning and gaining knowledge

It is our radiant sentiments to place on record our best regards and deepest sense of gratitude to our project supervisor Er. Bijendra Prajapati, who despite being extraordinarily busy with his duties, took out time to hear, guide, supervise and impart us with knowledge on various fields related to project.

We hereby would like to express our profound sense of gratitude to the Campus Chief, Er. Ram Prasad Poudel and Head of Department, Dr. Surya Prasad Adhikari,Er. DadiramDahal, AtmaramKayastha and Ram Lama along with Mr. Shiva Sharma and Mr. Prashant Kumar Deowho not only guided us, but also gave us valuable suggestions and guided in documentation and successful completion of the project. ${ }^{2}$

[1] S.S.Suprajha, K.Vijayan. "Design and Analysis of Helical Blade Wind Turbine”, International Journal of Innovative Research in Science, Engineering and Technology, Vol. 5, Issue 5, May 2016

[2] MD. Saddam Hussenet. al. "Design and Analysis of Vertical Axis Wind Turbine Rotors", International Journal on Recent Technologies in Mechanical and Electrical Engineering (IJRMEE), Volume: 2 Issue: 9, September 2015

[3] www.academia.edu/7278971/DESIGN_AND_FABRICATION_OF_SPIRAL_WIND_TURBINE_ BLADE (Retrieved on 22/1/2017)

[4] http://www.windside.com/products/ws-0_15 (Retrieved on 09/02/2017)

[5] https://upcommons.upc.edu/bitstream/handle/2099.1/19136/memoria (Retrieved on 09/02/2017) 